\title{
FOSSIL COLLECTING ON NATIONAL FOREST SYSTEM LANDS
}

KING*, C. Thomas, U.S. Forest Service, M\&GM Staff, PO Box 96090, Washington, DC 20090-6090, U.S.A.; MAY, Cathleen, U.S. Forest Service, RPST Staff, PO Box 25127, Lakewood, CO 80225, U.S.A.

The National Forests cover over 190 million acres of land and hosted 330 million visitor days of recreation use in 1994 . We are directed to manage the resources on these lands so that they will best meet the needs of the American people without impairing the productivity of the land. We are directed to use an approach that is interdisciplinary and that integrates the consideration of the various sciences.

How do we intend to accomplish this rather ambitious mission? Our answer is to follow what we call the "four P's of managing paleontological resources." The first step is to establish a PROFESSIONAL approach. We must have the services of qualified people. We now have our first two professional paleontologists.

Second, we need to develop POLICIES that can be understood and efficiently followed by FS field employees. Ideally, these policies would be based on a law that establishes the role of the Federal Government in fossil management. To date, we do not have that statement. We do have committment to work with other Federal agencies, such as the Bureau of Land Management, to insure that our policies are consistent. Policies are directed at the agency employee. If we need rules for the public, they are developed under the regulatory process.

Third, we must always deal with PAPERWORK. It is important that we have a program that limits paperwork--such as permits--to those cases where there is something of significance involved. It is important that the public can easily complete the paperwork when required. It is important that the scientist understands the value of the paperwork.

Fourth, we need to enter into PARTNERSHIPS with members of the fossil community so that we can use the expertise that already exists. We feel that cooperation is the only way we can succeed with out program.

As a working example of the multiple dimensions of the four P's, we have a program on the Comanche National Grassland in Colorado at a site called Picketwire Canyon. It hosts the longest and most speciose vertebrate trackway in North America. In addition, there are other resource values present, and all must be accounted for in our management plan. Broadiy stated, we will provide for scientific research, educational opportunities, and conservation of the value of the fossil record as preserved in the canyon.

Our biggest challange will be to secure as much access as possible by the full public, while maintaining the integrety of the paleontological resources. The area suffers from vandalism and theft due to its isolation. Even well meaning visitors contribute to the degradation of the site through unsupervised attempts at casting. On the positive side, we have developed a cooperative research partnership with University of Colorado, Denver; the Colorado State Geological Survey; and the United States Geological Survey. To shape an effective strategy, further scientific information is required. We created a new cost-sharing aggreement with UCD to provide that over the next three years. This will allow us to help support the research efforts of academia financially and logistically. 